\title{
Murder and the ICU
}

The Intensive Care Unit (ICU) is a place of technology, unusual drug formularies and rapid decisionmaking, all designed to help critically ill patients get better. However, these same factors can create an environment where a healthcare worker might systematically harm a patient without fear of detection or punishment. Such allegations are difficult to substantiate because evidence is so difficult to obtain and thus criminal prosecutions are rare. In addition, the damage that ongoing investigations can have on staff morale and interprofessional relationships is often underestimated. In light of recent well-publicized cases, these issues will come under increasing public scrutiny.

Many have argued that the most notorious case in which healthcare workers have systematically harmed patients in their care was that of Genene Jones [1]. She trained as a licensed vocational nurse (LVN) in Texas, USA, in the late 1970s. She was dismissed from two posts as a nurse. Her third post began in 1978 at a paediatric ICU in Texas. During the first year of her employment, a number of criticisms were levelled at Jones by her superiors. These included errors in drug administration, equipment use and emotional overinvolvement. However, it was noted that she would often volunteer to work extra shifts and care for the unit's sickest patients.

By 1981, 3 years after the beginning of her tenure, an unusual pattern of deaths was noted in the unit. The unexpected deaths were occurring in children whose condition was not necessarily considered as critical, during the evening shift. The deaths also occurred with greater than expected frequency in those being cared for by Jones. Her nursing colleagues dismissed these initial concerns. However, the medical staff requested increasing numbers of laboratory investigations after unexpected deterioration in children's health. The nursing staff were also asked by the unit's medical director to take extra precautions with drug administration and equipment settings.

Correspondence to: Gilbert Park, The John Farman Intensive Care Unit, Box 17, Addenbrooke's NHS Trust, Hills Road, Cambridge, CB2 2QQ, UK. E-mail: gilbertpark@compuserve.com; Fax: +44 (0)1223 217898

Accepted for publication November 2001 EJA 789
Despite this vigilance, excessive doses of heparin were given to one child on 2 consecutive days in direct breach of unit protocols. Subsequently, the death of a child following 'routine' cardiothoracic surgery in 1982 prompted the hospital administrator to set up an external investigation. This committee concluded that a variety of factors such as staff shortages, poor communication between staff and the variability of the junior medical staff were responsible for the spate of unexplained deaths. In addition, it recognized that Jones was possibly implicated. As a result of this inquiry, the hospital moved to replace all LVNs with registered nurses, thereby making Jones redundant in March 1982. The letter of reference given to her had no reservations about her abilities or her suitability as a paediatric intensive care nurse.

By August 1982, Jones was employed as a practice nurse in a rural community in Texas. A 14-month-old female was admitted to hospital suffering from unexplained seizures. Two months later this child died. Five other children had suffered seizures in unusual circumstances. Again, suspicions were aroused, but it was only after the discovery of a 'missing' vial of succinylcholine with puncture marks in the rubber cap that a criminal investigation was begun. This culminated in the conviction and sentencing of Jones to 60 years' imprisonment; more than 3 years after concerns had first been raised.

This case is unusual in that a conviction was obtained. Table 1 shows that this has not been the outcome of the majority of criminal prosecutions. Most cases of carers who kill patients in an ICU involve nurses. Court action against doctors has centred on negligence and euthanasia issues with a few exceptions such as the Manchester, UK, general practitioner P. Harold Shipman [2]. The ICU also features heavily - with some writers calling a murder allegation an occupational hazard of nursing the critically ill.

\section{Why do healthcare workers harm patients?}

People join the caring professions for a variety of reasons; equally, the motives for harming patients 
Table 1. Allegations of murder/grievous bodily harm against nurses in the UK/USA (adapted from Jones [4] with permission).

\begin{tabular}{lllll}
\hline Date & Location & Mode & Unit & Outcome \\
\hline 1975 & Michigan, USA & Pancuronium & ICU & Not guilty \\
1975 & Glasgow, UK & Insulin & Geriatrics & Mistrial \\
1980 & Nevada, USA & Ventilator tampering & ICU & Charges dropped \\
1980 & Chicago, IL, USA & Insulin & Surgical & Not charged \\
1981 & California, USA & Lidocaine & ICU & Death penalty \\
1983 & Texas, USA & Succinylcholine & Community & Guilty \\
1985 & Georgia, USA & Potassium chloride & ICU & Guilty \\
1985 & Maryland, USA & Potassium chloride & ICU & Acquitted \\
1988 & Florida, USA & Insulin & Nursing home & Guilty \\
1993 & Grantham, UK & Insulin & Paediatrics & Guilty \\
1996 & Bassetlaw, UK & Tampering & ICU & Guilty \\
1998 & Indiana, USA & Potassium chloride & ICU & Guilty \\
1998 & Newcastle, UK & Morphine & ICU & Charges dropped \\
\hline
\end{tabular}

may be just as diverse. Trust forms the basis of all healthcare. Carers who harm are so far outside this that it is commonly believed that such people must be mentally ill. In fact, only one nurse has pleaded insanity as a defence. Beverley Allitt, a paediatric nurse from Grantham, UK, suffered from Munchausen's syndrome [3] by proxy. This syndrome describes a person who fabricates signs of illness in another (usually a dependant) leading to secondary gain for the perpetrator [4]. It is believed that healthcare workers who suffer from this share many of the characteristics of other groups diagnosed with the condition such as a previous history of abuse and self-harm [5]. Analysis at the time of the Allitt enquiry suggested that three of the above cases (New York, Florida, Texas) [6] may have features of Munchausen's syndrome by proxy, but this is by no means a universal finding.

Other motives recorded for such actions include financial gain. This may be for individual gain such as the murder of elderly nursing-home residents or, alternatively, the winning of a sweepstake on which patient would die first. Justification of the continued provision of services because of the high mortality rate in a particular patient group may also be a factor (as was said in the case of Jones). Finally, the carer may believe they were maintaining the dignity of a person to whom conventional medicine had little to offer. Intensive care unit staff may also suffer from the charge of 'adrenaline (epinephrine)' medicine. The carer enjoys the drama of emergency lifesaving procedures and may induce cardiopulmonary arrest in a vulnerable patient so that they may be the hero/heroine. This can often be difficult to detect. By its very nature, critical care medicine attracts people who thrive in such an environment and who tend to have a black sense of humour, which could be misconstrued if taken out of context. The patients they care for also tend to be the most unstable, so clusters could occur simply by chance leading to a crime of just 'being there' or 'having a bad run' [7]. Finally, some carers may see death as inevitable in some patients and hasten it so they can counsel the relatives.

\section{Detection of suspicious deaths}

The British legal system so far has refused to declare guilt by association - that is, a person is guilty if, on the basis of probability, they were involved at the time of a major change in a patient's condition more often than could be explained by chance alone. This sort of case control study has been used to support other evidence, but of itself, it is considered circumstantial. One of the first of these was undertaken by the Centre for Disease Control (CDC) in response to a series of deaths in a children's cardiology ward where the epidemiological evidence showed that the relative risk of a 'terminal deterioration' was 8.2 for the nurse who was charged with murder. There was a relative risk of 64.6 [8] for a second nurse, who has never been charged, again emphasizing the way in which the courts have viewed such epidemiological evidence. If this type of analysis can only be conducted retrospectively, how can a train of suspicious events be identified? Yorker [8] identified a number of factors including the following:

- A significant increase in cardiopulmonary arrests, or deaths, or both, particularly in patients not thought to be in immediate danger;

- An unusually high rate of successful resuscitation;

- Multiple events in the same patient;

- Events occurring more often in a particular shift.

It has also been suggested that postmortem investigations revealing toxic amounts of an injectable 
substance should be used as a marker of professional homicide. However, this seems belated and requires some knowledge of the putative substance and a high index of suspicion.

\section{Dealing with the situation}

What action should be taken if a carer is suspected of harming patients? Legally, responsibility for the investigation of suspicious deaths rests with the coroner and the police; however, it is the healthcare professionals who will be the first to raise suspicion. An awareness of those features that might indicate foul play is needed. They should make detailed records about the nature of the event and the persons present, take great care to preserve potential evidence such as infusion sets and consider taking specimens for later toxicological analysis [9]. From an institutional perspective, the issues may be different; there is the concern of damage limitation in respect to not only patients, but also the institution itself and to other members of staff [10].

The Clothier Report [11], conducted after the Allitt case, suggested that people working with vulnerable patients should undergo pre-employment screening to detect those who were felt to pose significant risk - particularly mental health problems. However, mental illness is not thought to be a major factor in those cases currently in the public domain and therefore the positive predictive value of such information is limited. Such strategies discriminate against people with any mental illness; even if it is not relevant in the day-to-day performance of a job. The best way to deal with this seems to be prevention; an awareness of the possibility and improving practices such as the use of nurse-controlled and dangerous drugs, two staff signatures for every potentially harmful treatment and a willingness to react rapidly to any concerns. New technology will also reduce the risk - such as patient-controlled analgesia systems to give intermittent bolus doses of morphine rather than having syringes at the end of the bed. Such measures should also raise standards of care generally and thereby minimize the chance of a genuine mistake.

Healthcare workers who harm patients intentionally are rare, although the practice of euthanasia may be relatively common [12]. Anyone who is sufficiently determined can circumvent the detection and investigation procedures. The best strategy is to implement procedures that improve the quality of care and will minimize harm to patients. The intensive care nurse who murders a patient is exceedingly rare, but there is great scope for this type of accusation in this environment. Should you ever face an allegation take the advice of Charbonneau: 'If suspicion places you in a suspect category, recognise that your interests are distinct from the hospital's interests and the prosecutor's interests. Get a lawyer, ask your 'professional' association for help and never resign' [13].

\section{G. R. Park, S. N. Khan \\ John Farman Intensive Care Unit Addenbrooke's Hospital Cambridge, UK}

\section{References}

1. Elkind P. The Death Shift. New York, USA: Viking/ Penguin, 1993.

2. O'Neill W. Doctor as murderer. Br Med J 2000; 320: 329-330.

3. Asher R. Munchausen's syndrome. Lancet 1951; i: 339-341.

4. Jones C. Is a murder charge an occupational hazard of intensive care nursing? Intensive Crit Care Nurs 1998; 14: 208-212.

5. Meadow R. Munchausen syndrome by proxy - the hinterland of child abuse. Lancet 1977; ii: 343-345.

6. Repper J. Munchausen syndrome by proxy in health care workers. J Adv Nur 1995; 21: 299-304.

7. Martin D. Nurses who murder. Nurs Stand 1989; 3: 19-20.

8. Buehler JW, Smith LF, Wallace EM, Heath CW Jr, Kusiak R, Herndon JL. Unexplained deaths in a children's hospital. An epidemiologic assessment. $N$ Engl J Med 1985; 25: 211-216.

9. Yorker B. Nurses accused of murder. Am J Nurs 1988; 88: 1327-1328.

10. James DS, Leadbeatter S. Detecting homicide in hospital. J R Coll Physicians Lond 1997; 31: 296-298.

11. Clothier C. The Allitt Inquiry. London, UK: HMSO, 1994.

12. Asch D. The role of critical care nurses in euthanasia and assisted suicide. N Engl J Med 1996; 334: 1374-1379.

13. Charbonneau L. Paech speaks out on Grange. Canad Nurse 1984; 80: 14 . 